\title{
Optimum design of dynamic voltage restorer for voltage sag mitigation in distribution network
}

Deshpande Chinmay V., Deshpande Chaitanya V.

Departement of Electrical Engineering, ZES ZCOER, India

\begin{tabular}{|c|c|}
\hline Article Info & ABSTRACT \\
\hline $\begin{array}{l}\text { Keywords: } \\
\text { Dual pq theory } \\
\text { E-Z source inverter } \\
\text { SRF Control Technique } \\
\text { Voltage sag }\end{array}$ & $\begin{array}{l}\text { DVR is power electronic based device used for mitigation of voltage sag } \\
\text { problem. In this paper, various inverter topologies such as Voltage source } \\
\text { inverter, Z source inverter and Embedded Z source inverter are used and } \\
\text { compared for operation of DVR. Here dual p-q theory is implemented as } \\
\text { control technique which have excellent transient response and speed. } \\
\text { Different inverter configurations are implemented for DVR and its } \\
\text { simulation results are presented and compared. It has been observed that } \\
\text { Embedded EZ source inverter topology is found to be effective. The } \\
\text { Embedded EZ source inverter topology and its hardware results are presented } \\
\text { and compared. }\end{array}$ \\
\hline \multicolumn{2}{|l|}{ Corresponding Author: } \\
\hline \multicolumn{2}{|c|}{$\begin{array}{l}\text { Deshpande Chinmay V., } \\
\text { Departement of Electrical Engineering, } \\
\text { ZES ZCOER, Narhe, Pune, Maharashtra, India } \\
\text { Email: chinmaydeshpande123@gmail.com }\end{array}$} \\
\hline
\end{tabular}

\section{INTRODUCTION}

Voltage sag lasting up to 3 to 4 cycle causes wide range of customer's sensitive equipment to be dropout. Ultimately, voltage sag creates economic losses along with wasting the resources [1]. It is necessary to boost promptly the load side voltage in the event of fault or switching of load in order to avoid disturbances and voltage sag situation. Out of various devices that may be used to mitigate power quality problem, Dynamic Voltage Restorer (DVR) is one which is used to phase out voltage sag and swell situation in distribution line. A power electronic DC to AC solid state switching converter used as series compensator that can be utilized to protect crucial loads from all supply side disturbances other than disturbances is called as "Dynamic Voltage Restorer (DVR)"[2].

The DVR can compensate for inductive drop in the line by inserting the voltage in quadrature with feeder current [3]. The DVR can also limit fault current by injecting leading voltage in quadrature with the fault current thereby increasing the effective fault impedance of the distribution feeder [4]. Now days, inverters are like a small mandatory electronic device which are extensively used due to its global function of transforming DC to AC [5]. Even though output voltage obtained is of having reduced harmonic level in case of VSI but if two switches on same phase leg turns ON, short circuit occurs this is the killer of inverter. Whenever DC link voltage falls below certain critical level, injection capability of DVR affects in case of VSI topology [6]. In case of CSI, at least one switch from upper leg and one switch from lower leg have to be turned $\mathrm{ON}$ to avoid an open circuit condition. In order to avoid an open circuit condition, overlapping time is provided for operation of switches which leads to distortion in output voltage and to correct it, there is the requirement of separate filter. Another alternative is $\mathrm{Z}$ source inverter which has an additional unique $\mathrm{X}$ shaped impedance network is connected at converter output side [7].

This paper proposes new inverter topology for DVR such as Embedded Z source inverter along with dual p-q control technique. The proposed control technique is able to detect voltage sag very well with faster 
speed. The proposed inverter configuration is tested with hardware prototype. All disadvantages associated with conventional inverters are overcome in Embedded Z source inverter.

\section{EMBEDDED Z SOURCE INVERTER}

Most of the application has requirement of both buck and boost capability and for that purpose instead of using VSI or CSI, Z source inverter is viable solution. Presence of Z network in case of ZSI highly improves the reliability of inverter since additional one shoot-through condition is present which is no longer present in conventional VSI and CSI [8]. Because of cross-conduction or additional shoot through condition present, it is free from short circuit or open circuit problem in case of $\mathrm{Z}$ source inverter [9].

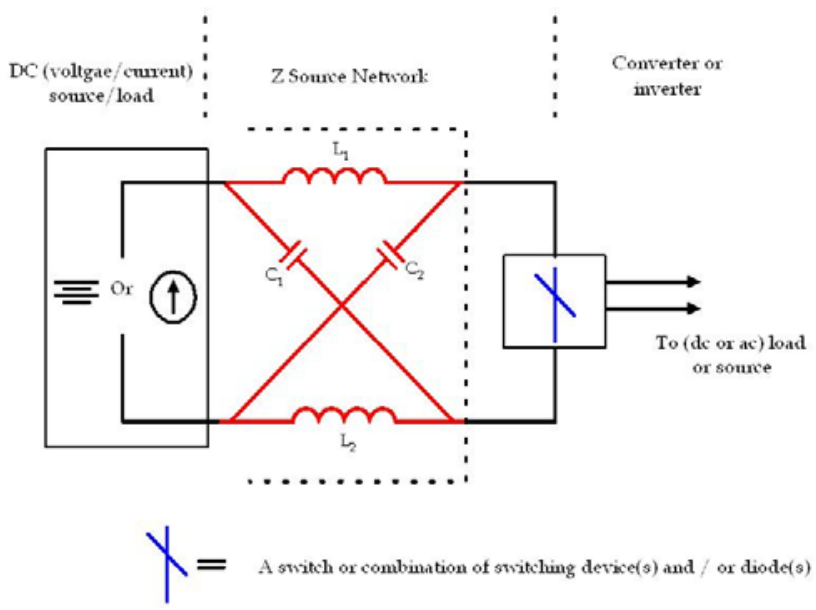

Figure 1. Impedance $(Z)$ source inverter

Instead of using separate LC filtering in case of VSI, CSI or ZSI, new family of ZSI is incorporated which is Embedded Z source inverter (as shown in Figure 2). Basically EZ source inverter produce the same gain as the Z-source inverter but with smoother and smaller current/voltage maintained across the dc input source and within the impedance network [10]. For this purpose there is no any requirement of any additional passive filter and hence because of this total cost and complexity gets reduced. Embedded EZ-source inverter have the advantages of lower cost, can be applied to all ac-ac, dc-dc, acdc, dc-ac power conversion, has low current compared with the traditional source inverter, does not affect the Electromagnetic Interference noise, drawing a smoother current from the dc input sources [11].

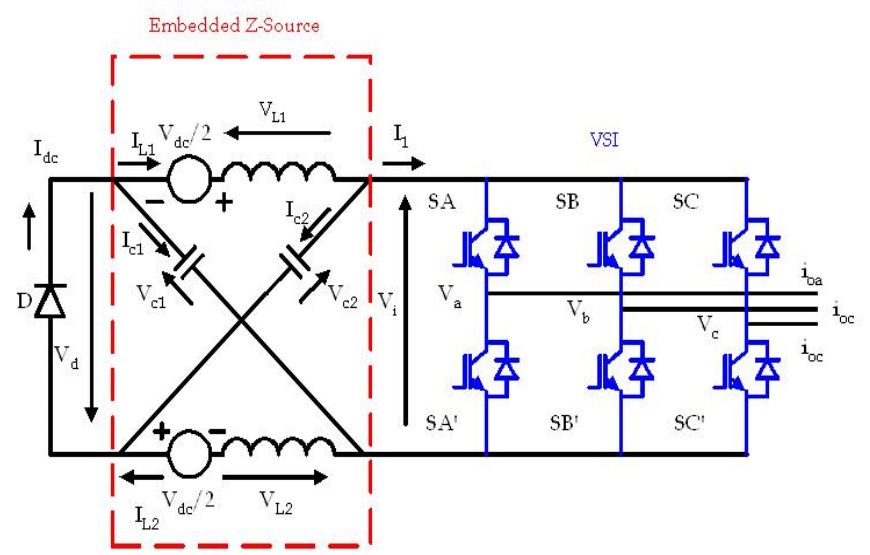

Figure 2. Embedded impedance $(Z)$ source inverter

Optimum Design of Dynamic Voltage Restorer for Voltage Sag Mitigation in ... (Deshpande Chinmay V) 


\section{PROPOSED p-q THEORY}

In this paper, dual p-q theory is implemented which gives series voltage compensation [12]. The main assumption in case of dual p-q theory is that current and real and imaginary powers are known and voltage component should be calculated. The phase voltages at the load terminal and the line currents are measured and transformed into $\alpha \beta$ the reference frames [13]. The matrix representation of line voltage and line current into $\alpha \beta$ reference frames is given by following equations as,

$$
\begin{aligned}
& {\left[\begin{array}{l}
U_{0} \\
U_{\alpha} \\
U_{\beta}
\end{array}\right]=\sqrt{\frac{2}{3}}\left[\begin{array}{ccc}
\frac{1}{\sqrt{2}} & \frac{1}{\sqrt{2}} & \frac{1}{\sqrt{2}} \\
1 & -\frac{1}{2} & -\frac{1}{2} \\
0 & \frac{\sqrt{3}}{2} & -\frac{\sqrt{3}}{2}
\end{array}\right]\left[\begin{array}{l}
U_{a} \\
U_{b} \\
U_{c}
\end{array}\right]} \\
& {\left[\begin{array}{l}
C_{0} \\
C_{\alpha} \\
C_{\beta}
\end{array}\right]=\sqrt{\frac{2}{3}}\left[\begin{array}{ccc}
\frac{1}{\sqrt{2}} & \frac{1}{\sqrt{2}} & \frac{1}{\sqrt{2}} \\
1 & -\frac{1}{2} & -\frac{1}{2} \\
0 & \frac{\sqrt{3}}{2} & -\frac{\sqrt{3}}{2}
\end{array}\right]\left[\begin{array}{l}
C_{a} \\
C_{b} \\
C_{c}
\end{array}\right]}
\end{aligned}
$$

Where $U_{\alpha}$ and $U_{\beta}$ is the $\alpha \beta$ representation of line voltage and $C_{\alpha}$ and $C_{\beta}$ is the $\alpha \beta$ representation of line current. From the $U_{\alpha}$ and $U_{\beta}$ and $C_{\alpha}$ and $C_{\beta}$ the real and imaginary powers of the loads i.e. instantaneous power components are calculated as:

$$
\left[\begin{array}{l}
p \\
q
\end{array}\right]=\left[\begin{array}{cc}
C_{\alpha} & C_{\beta} \\
-C_{\beta} & C_{\alpha}
\end{array}\right]\left[\begin{array}{l}
U_{\alpha} \\
U_{\beta}
\end{array}\right]
$$

After that an undesirable power sources $p_{c}$ and $q_{c}$ are selected. From these power portions of the load powers and line currents, the compensating voltages are calculated and inserted "instantaneously" in the power system by series compensator. [14] From the above equation, we can determine value of $U_{\alpha}$ and $U_{\beta}$ in terms of $p_{c}$ and $q_{c}$.

$$
\left[\begin{array}{l}
U_{\alpha} \\
U_{\beta}
\end{array}\right]=\frac{1}{{C_{\alpha}{ }^{2}+C_{\beta}{ }^{2}}_{C}}\left[\begin{array}{cc}
C_{\alpha} & -C_{\beta} \\
C_{\beta} & C_{\alpha}
\end{array}\right] *\left[\begin{array}{l}
p_{c} \\
q_{c}
\end{array}\right]
$$

Where, $\mathrm{p}_{\mathrm{c}}$ and $\mathrm{q}_{\mathrm{c}}$ are powers that are selected. With these oscillating powers, it is possible to calculate the instantaneous voltages that have to be injected by the DVR to compensate for the load voltage by using above equation.

\section{IMPLEMENTATION OF VARIOUS INVERTER TOPOLOGIES: A CASE STUDY}

There are three cases for different inverter connected to DVR. The results for each case are demonstrated along with its THD analysis. We can compare all three inverters on the basis of THD values obtained.

\subsection{Distribution line model with DVR based on voltage source inverter}

Detail simulations are performed on DVR test system using MATLAB SIMULINK [14]. A line of $13 \mathrm{KV}$ is step up to $115 \mathrm{KV}$ for transmission purpose and then it is again step down by using distribution transformer having rating of $115 \mathrm{KV} / 11 \mathrm{KV}$. Here it is considered that, there load suddenly imposed on system feeder B for the duration of 0.04 to $0.1 \mathrm{sec}$. [15]. The transition time of circuit breaker is 0.04 to 0.1 i.e. during that period only load gets acted upon line due to which voltage sag is experienced by load feeder B. Basically VSI is boost type of inverter which gives good output response for the operation of DVR. Following Figure 3 shows simulation result for operation of DVR based on voltage source inverter. From the Figure 3, it is clear that during fault condition or switching condition, DVR corrects the voltage instantly. The THD analysis of DVR with VSI comes out to be $15.09 \%$ for supply voltage and $2.70 \%$ for current. 

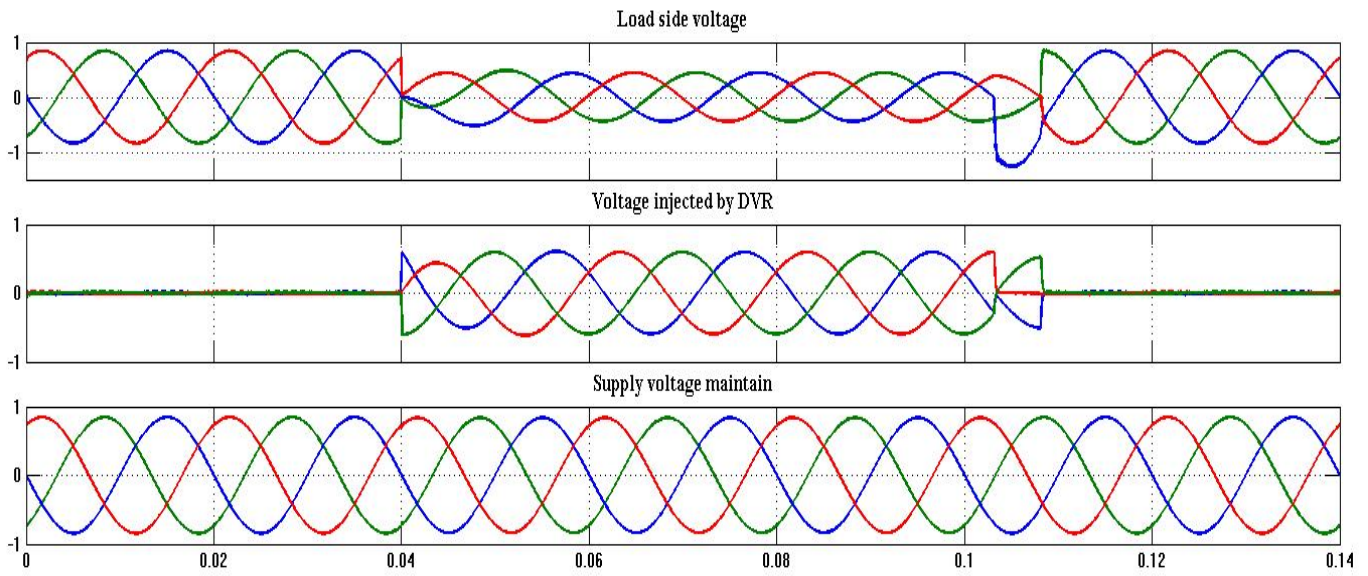

Figure 3. MATLAB simulation result of distribution line model with DVR based on voltage source inverter

\subsection{Distribution line model with DVR based on impedance z source inverter}

In case of ZSI is that as capacitor and inductor both are used in DC link, it acts as constant high impedance voltage source. Sometimes if misfiring of switches is allowed which is not permissible in VSI. Harmonic distortion is low with less power losses and hence efficiency of ZSI is more as compared with VSI/CSI. Diode D connected is usually needed for preventing reverse current flow. The value of inductor and capacitor for impedance part of ZSI is calculated as $25 \mathrm{mH}$ and $5 \mathrm{~F}$. Following Figure 4 shows MATLAB Simulation result of voltage sag having DVR based on $Z$ source inverter. The THD analysis of DVR with ZSI comes out to be $0.11 \%$ for supply voltage and $6.19 \%$ for current.

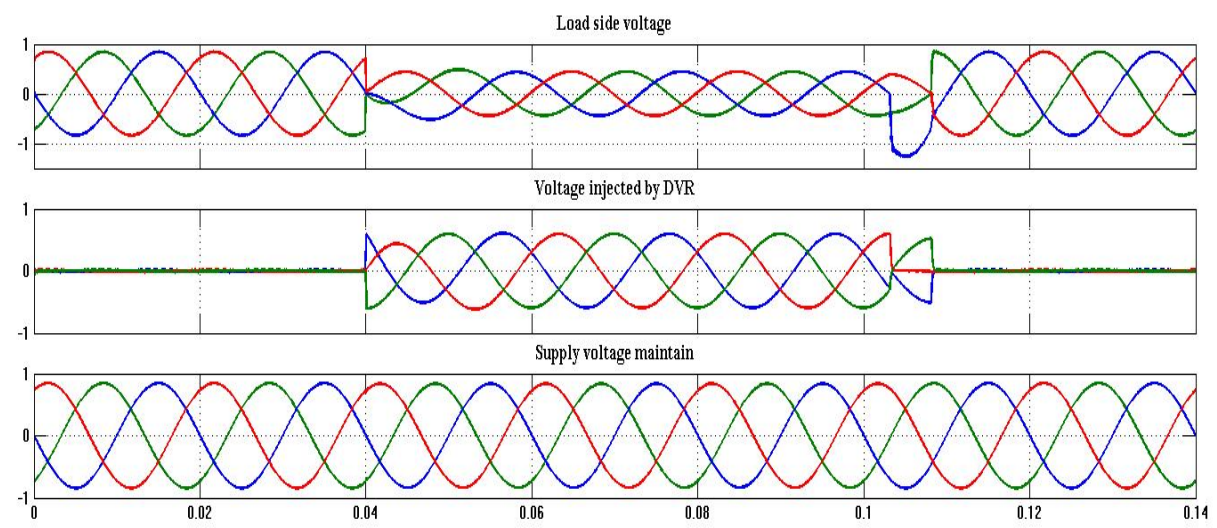

Figure 4. MATLAB Simulation result of voltage sag having DVR based on Z source inverter

\subsection{Distribution line model with DVR based on embedded impedance z source inverter}

Following Figure 5 shows simulation of DVR based on EZ source inverter with dual p-q theory. Supply side voltage and current first gets converted to $\alpha \beta$ reference frame by Clark's transformation. From these values instantaneous active and reactive powers are calculated. As seen from simulation result, response time of DVR with EZ source inverter is fast as compared with VSI and ZSI. Also the requirement of filter reduces in case of EZ source inverter. Compare with ZSI, EZSI draws smoother current from input dc sources. Both buck-boost capabilities are obtained by using EZSI. Whenever load is imposed on the system, the control system calculates difference between pre-sag and during sag voltage and PWM pulses are given to EZSI.

Optimum Design of Dynamic Voltage Restorer for Voltage Sag Mitigation in ... (Deshpande Chinmay V) 


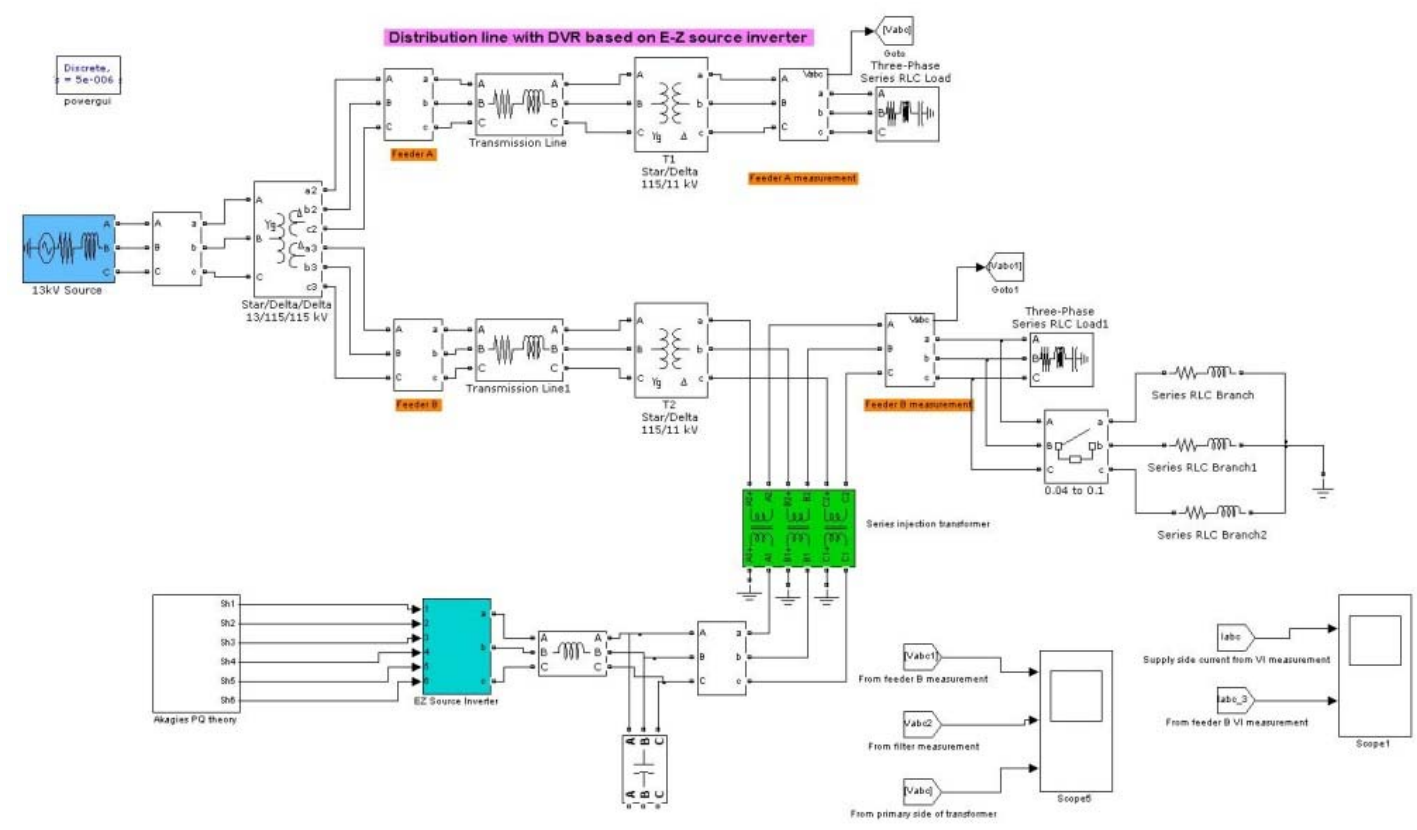

Figure 5. Distribution line model with DVR based on Embedded Z source inverter

\section{EXPERIMENTAL VALIDATION \& RESULTS}

To verify the effectiveness of proposed system of DVR based on Embedded Z source inverter, prototype has been built based on proposed system which is as shown in Figure 5. The main supply is single phase, $50 \mathrm{~Hz}, 230 \mathrm{~V}$ which is step down to $110 \mathrm{~V}$. The filter capacitor is $470 \mathrm{~F}$. To start up the test, first of all load of $25 \mathrm{~W}, 1 \mathrm{mH}$ inductor is connected. Driver circuit is operated with another step down transformer of rating $230 / 12 \mathrm{~V}$ which is converted into pulsating DC by using bridge rectifier (W10). The output from bridge rectifier is $12 \mathrm{~V}$ pulsating DC which is converted into $+5 \mathrm{~V}$ by using IC 7805 voltage regulator. The purpose of IC voltage regulator is to provide constant DC voltage of $+5 \mathrm{~V}$ to the PIC micro controller (PIC16F877A). Driver circuit is used for isolation purpose. In order to trigger MOSFET, the voltage requirement is $20 \mathrm{~V}$. Hence the $12 \mathrm{~V}$ AC from driver circuit transformer is amplified by using two amplifiers CK100 and 2N2222 connected back to back. The boosted voltage is then converted to DC by using diode IN4007 as a half wave rectifier. Single phase EZ source inverter converts this DC voltage into AC for injection into system. Capacitor of 100 micro farad and $1 \mathrm{mH}$ inductor is used as filter in impedance network of EZ source inverter. Two $9 \mathrm{~V}$ batteries are used as energy storage in case of EZ source inverter which acts as input to it. The voltage is injected through injected transformer of rating $12 \mathrm{~V}$. The rating of each component in hardware prototype is listed below in Table 1.

Table 1. Main specifications of hardware implementation of EZ source based DVR.

\begin{tabular}{|c|c|c|}
\hline Sr. No. & Component & Values \\
\hline 1. & Single phase transformer & $230 / 110 \mathrm{~V}$ \\
\hline 2. & Driver circuit transformer & $230 / 12 \mathrm{~V}$ \\
\hline 3. & Load & $25 \mathrm{~W}$ bulb as resistive load, $1 \mathrm{mH}$ inductor \\
\hline 4. & Injection Transformer & $12 \mathrm{~V}$ \\
\hline 5. & Filter Capacitor & $\begin{array}{l}100 \mu F / 25 \mathrm{~V}=\text { for reduction of ripples from pulsating. } \\
10 \mu F / 25 \mathrm{~V}=\text { for maintaining stability of the voltage at the } \\
\text { load side. }\end{array}$ \\
\hline 6. & DC Storage Battery & Two Batterys of 9V \\
\hline 7. & Filter Inductor & $1 \mathrm{mH}$ \\
\hline
\end{tabular}

The supply side voltage comes out to be $98.9 \mathrm{~V}$ and there is drop across load which comes out to be 86.2V. The switch is provided to connect DVR to the system. When DVR connects to the system and injects 
the voltage, bulb glows brightly. After compensation, load voltage is maintained at 93.4 V. Following Figure 6(a), 6(b) and 6(c) shows actual hardware readings.

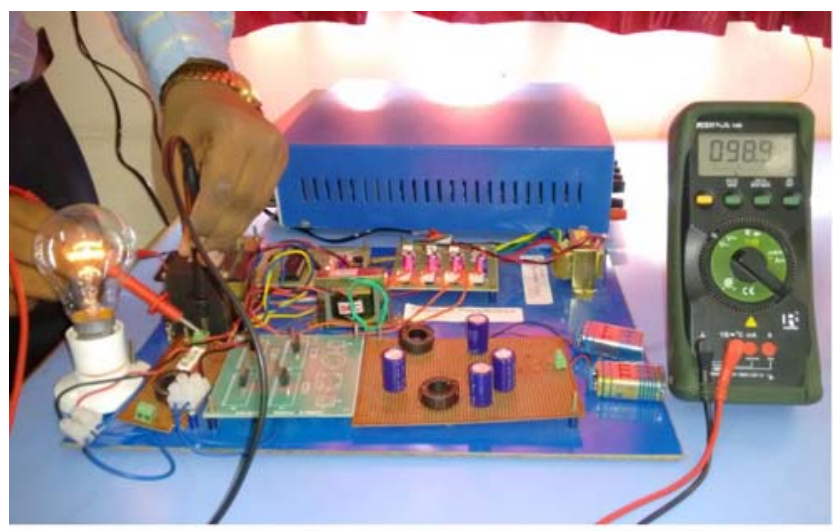

(a)

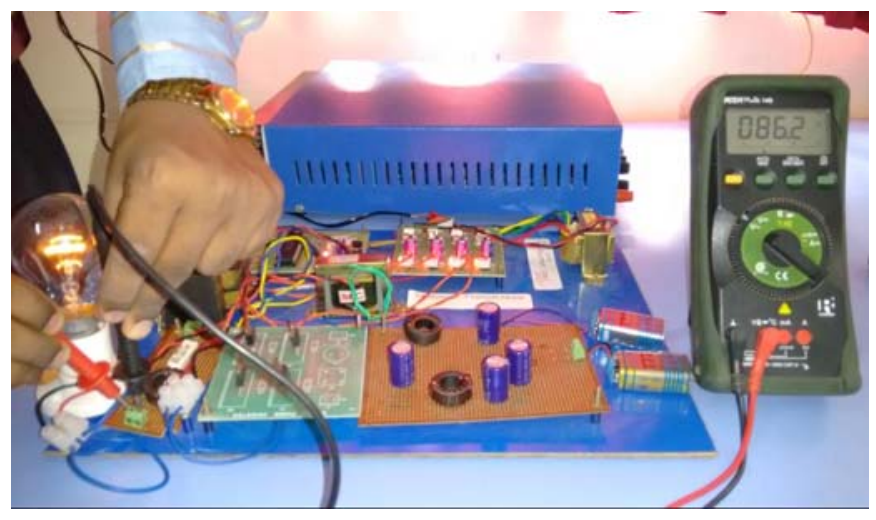

(b)

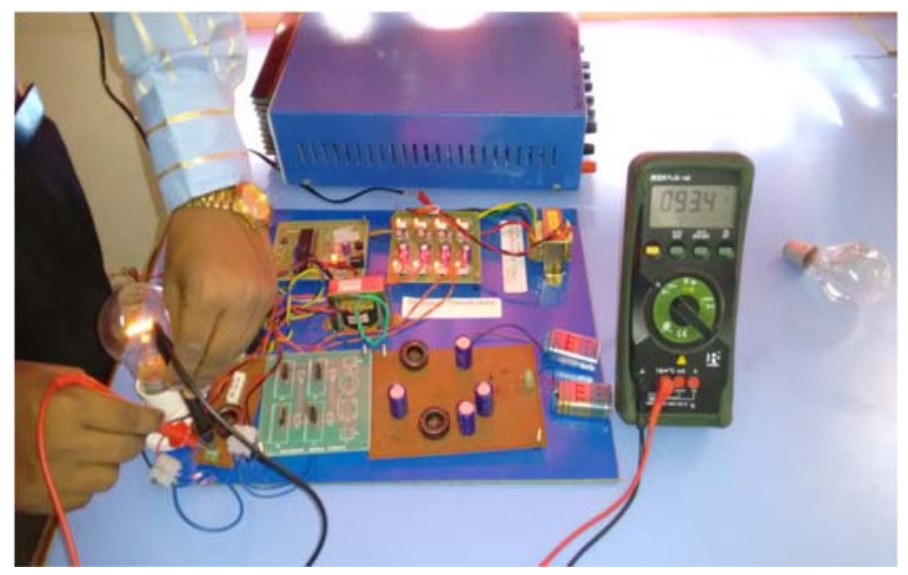

(c)

Figure 6. Hardware implementation of DVR based on EZ source inverter; (a) supply side voltage of DVR based on EZ source inverter, (b) load side voltage without DVR connected, (c) hardware result for load side voltage with DVR connected. 
By considering the parameters of hardware prototype in MATLAB simulation, results obtained are as shown in Figure 7.

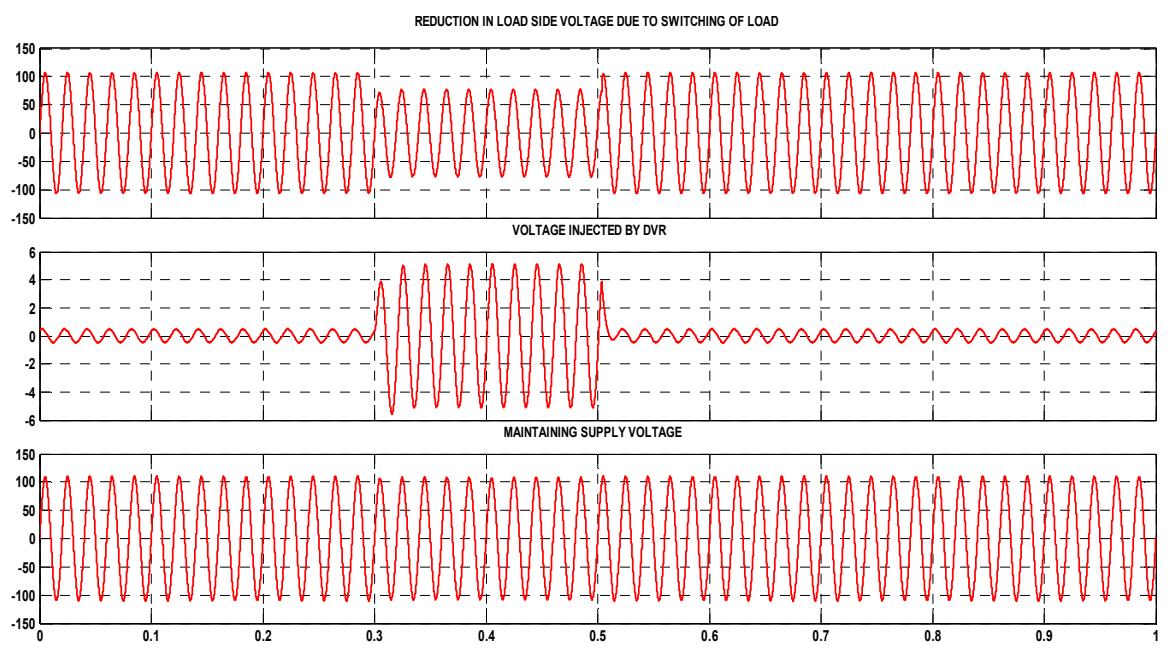

Figure 7: MATLAB simulation result for single phase DVR based on Embedded Z source inverter

In simulation the value of load resistance is calculated by considering $25 \mathrm{~W}$ bulb and $110 \mathrm{~V} \mathrm{AC}$ supply which comes to be $484 \mathrm{ohm}$. From the single phase simulation and hardware prototype, it is to be seen that DVR is capable of mitigating voltage sag condition. The results are shown in Table 2 below.

Table 2. Simulation result of software and hardware implementation of EZ source based DVR

\begin{tabular}{llll}
\hline Sr. No. & Component & Simulation Results & Hardware Results \\
\hline 1. & Supply side voltage & $102 \mathrm{~V}$ & $98.9 \mathrm{~V}$ \\
2. & Load side voltage before connection of DVR & $95 \mathrm{~V}$ & $86.2 \mathrm{~V}$ \\
3. & Load side voltage after DVR connected & $100 \mathrm{~V}$ & $93.4 \mathrm{~V}$ \\
\hline
\end{tabular}

\section{THD ANALYSIS}

Following table 3 shows FFT analysis of DVR based on various inverter topologies. The total harmonic distortion (THD) of a signal is a measurement of the harmonic distortion present in any given signal.

It has been observed that reduction in voltage THD and current THD in case of Embedded E-Z source inverter is of $99.47 \%$ and $85.56 \%$ respectively compared with VSI topology $27.27 \%$ and $93.7 \%$ compared with ZSI topology.

Table 3. THD analysis for simulations of DVR connected with different inverter topologie

\begin{tabular}{llll}
\hline Sr. No. & Type of Inverter & Voltage THD $(\%)$ & Current THD $(\%)$ \\
\hline 1. & Voltage Source Inverter & $15.09 \%$ & $2.70 \%$ \\
2. & Impedance Z Source Inverter & $0.11 \%$ & $6.19 \%$ \\
3. & Embedded Impedance (EZ) Source Inverter & $0.08 \%$ & $0.39 \%$ \\
\hline
\end{tabular}

\section{CONCLUSION}

This paper presents one of the custom power devices, which is referred to as dynamic voltage restorer based on various inverter topologies such as VSI, ZSI and EZSI. In order to investigate whether the DVR is able to deal with voltage sag problem, Matlab Simulink was selected in order to simulate the system and mitigate the voltage sag. The THD analysis is carried out which shows that in case of Embedded Z source inverter, voltage THD comes out to be $0.08 \%$ and current THD comes out to be $0.39 \%$ in the three phase simulation which is within specified limit as per IEEE standard. Also along with EZ source inverter

Int J Pow Elec \& Dri Syst, Vol. 10, No. 3, Sep 2019 : $1364-1372$ 
topology, problems associated with VSI, CSI are overcomed. Hence the DVR based on EZ source inverter gives fast dynamic response along with lower cost which can mitigate long duration voltage sag effectively in distribution network.

The hardware prototype model shows that DVR is able to mitigate drop across load. The results of hardware and simulation are compared which comes out to be nearly same. These results also show clearly that DVR handles situation of voltage sag efficiently by correcting load side voltage rapidly.

\section{REFERENCES}

[1] Mahmoud Zadehbagheri, Rahim lldarabadi,Majid Baghaei Nejad, "Review of Dynamic Voltage Restorer Application for Compensation of Voltage Harmonics in Power Systems", Indonesian Journal of Electrical Engineering and Computer Science, Vol. 5, No. 1, pp. 58 71; January 2017.

[2] G. Ramya, V. Ganapathy, P. Suresh, "Power Quality Improvement Using Multi-Level Inverter Based DVR and DSTATCOM Using Neuro-Fuzzy Controller", International Journal of Power Electronics and Drive System (IJPEDS), Vol. 8, No. 1, pp. 316 324; March 2017.

[3] Deshpande Chinmay V and Sanjay A. Deokar, Enhancement of Power Quality Using Dynamic Voltage Restorer Based on EZ Source Inverter", International Journal of Advance Research in Electrical, Electronics \& Instrumentation Engineering, ,Volume 4, issue 2; 2015.

[4] Yushan Liu, Haitham Abu-Rub, Baoming Ge, Frede Blaabjerg, Omar Ellabban; Poh Chiang Loh, " Z-Source Inverter", in Impedance Source Power Electronic Converters, 1, Wiley-IEEE Press, 2016, pp.424.

[5] T. Yu, X. Shaojun, Z. Chaohua, and X. Zegang, “ Improved Z-Source Inverter With Reduced Z-Source Capacitor Voltage Stress and Soft-Start Capability”, IEEE Transactions on Power Electronics, vol. 24, no. 2, pp. 409-415, 2009.

[6] P. C. Loh, D. M. Vilathgamuwa, C. J. Gajanayake, L. T. Wong, and C. P. Ang, "Z-source current-type inverters: Digital modulation and logic implementation,” IEEE Trans. Power Electron., vol. 22, no. 1, pp. 169- 177, Jan. 2007.

[7] Yushan Liu, Haitham Abu-Rub, Baoming Ge; Frede Blaabjerg, Omar Ellabban, Poh Chiang Loh, "Typical Transformer-Bases Z-Source/Quasi-Z-Source Inverters", in Impedance Source Power Electronic Converters, 1, Wiley-IEEE Press, pp.424; 2016.

[8] R. Sinthiya Jothi, S. Frederick, "Design and simulation of T-Z source inverter system", International Journal of Scientific \& Engineering Research, Volume 5, Issue 6, June-2014, ISSN 2229-5518.

[9] Rani Mathews, Anupama Sisodia, "Analysis of Improved Trans Z-Source Inverter using PWM Technique", International Journal of Engineering Research \& Technology (IJERT), Vol. 3 Issue 5, May - 2014, ISSN: 22780181.

[10] S. Nagarajan and N. Rajendran, "Comparison of Fault Diagnostics on Z-Source and Trans Z-Source Inverter Fed Induction Motor Drives", Indian Journal of Science and Technology, Vol 8(32), November 2015, DOI: 10.17485/ijst/2015/v8i32/87868.

[11] W. Qian, F. Z. Peng and H. Cha, "Trans-Z-Source Inverters", in IEEE Transactions on Power Electronics, vol. 26, no. 12, pp. 3453-3463, Dec. 2011. doi: 10.1109/TPEL.2011.2122309.

[12] Swathyprakash and Rani S, "Modified Trans-Z-Source Inverter with Continuous Input Current and Improved Boost Factor", International Conference on Electrical, Electronics, and Optimization Techniques (ICEEOT) - 2016, 9781-4673-9939-5/16/ C2016 IEEE.

[13] Deshpande Chinmay V., Patil Rajashri J. and Deokar Sanjay A., "Different control schemes for power quality improvement using embedded Z source based Dynamic Voltage Restorer", 2015 International Conference on Energy Systems and Applications, Pune, 2015, pp. 135-140.

[14] R. Omar and N. A. Rahim, "Modeling and simulation for voltage sags/swells mitigation using dynamic voltage restorer (DVR)", in Power Engineering Conference, 2008. AUPEC 08 Australasian Universities, IEEE, pp. 1-5, 2008.

[15] Deshpande Chinmay V., Deshpande Chaitanya V. \& Dr. S.A. Deokar, "Performance Evaluation of Dynamic Voltage Restorer Based on Transformer based Z Source Inverter", International Journal of Power Electronics and Drive System (IJPEDS), Vol. 8, No. 03, pp: 1401-1408; September 2017. 


\section{BIOGRAPHIES OF AUTHORS}

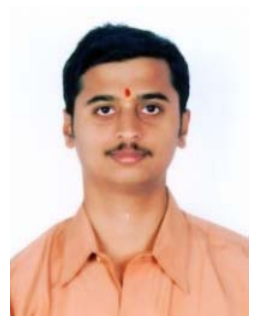

Mr. Chinmay V. Deshpande received his BE degree in Electrical Engineering from Savitribai Phule University (formerly Pune University) - India in 2013, and is ME in Electrical Power Systems from Savitribai Phule University (formerly Pune University) - India in the year of 2015. Currently he is working in Department of Electrical Engineering at Zeal Education societies, Zeal college of Engineering and Research as Assistant Professor. His field of interest includes Power Systems and Power Quality, FACTS, Machine design.

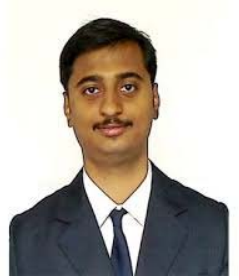

Mr. Chaitanya V. Deshpande received his BE degree in Electrical Engineering from Savitribai Phule University (formerly Pune University) - India in 2013, and is ME in Electrical Power Systems from Savitribai Phule University (formerly Pune University) - India in the year of 2015. Currently he is working in Department of Electrical Engineering at Zeal Education societies, Zeal college of Engineering and Research as Assistant Professor. His field of interest includes Power Systems, FACTS. 